\title{
RESPIRAÇÃO MICROBIANA COMO INDICADOR DA QUALIDADE DO SOLO EM ECOSSISTEMA FLORESTAL
}

\author{
Martha Lucía Peña Peña*, Renato Marques **, Marcelo Cabral Jahnel***, Adilson dos Anjos**** \\ * Bióloga, M.Sc., Curso de Pós-Graduação em Ciência do Solo, UFPR - marthalupe@bol.com.br \\ ** Eng. Florestal, Dr., Depto. de Solos e Engenharia Agrícola, UFPR - rmarques@ufpr.br \\ *** Eng. Agrônomo, Dr., Centro de Ciências Agrárias e Ambientais, PUC - jahnel@rla01.pucpr.br \\ **** Eng. Agrônomo, M.Sc., Depto. de Estatística, UFPR - adilson.anjos@est.ufpr.br \\ Recebido para publicação: 22/08/2002 - Aceito para publicação: 28/03/2005
}

\begin{abstract}
Resumo
Respiração microbiana como indicador da qualidade do solo em ecossistema florestal. O presente trabalho foi realizado na Floresta Estadual do Palmito, Paranaguá, PR, em área coberta originalmente com Floresta Ombrófila Densa das Terras Baixas, que sofreu processo de degradação antrópica, apresentando, hoje, áreas representativas de diversas fases da regeneração secundária. Esta pesquisa visou avaliar respostas de microrganismos às mudanças ambientais da floresta em processo de regeneração. Foram selecionadas três áreas, representativas de diferentes fases da sucessão secundária deste ecossistema, onde foram coletadas amostras dos horizontes superficiais do solo: F, H e A, nas quatro estações climáticas. Nas amostras coletadas, a avaliação da atividade microbiana foi feita pela quantificação da respiração microbiana. Os resultados mostraram que a produção de $\mathrm{CO}_{2}$ nos horizontes do solo foi decrescente no seguinte sentido: $\mathrm{F}>\mathrm{H}>\mathrm{A}$. Foi também superior na fase avançada da vegetação, sobretudo no horizonte $F$. As estações do ano não mostraram efeito conclusivo sobre a atividade microbiana. A melhoria da qualidade do solo, ao longo da evolução florestal, foi caracterizada indiretamente através da determinação da respiração microbiana, o que sugere esta análise como ferramenta indicadora de qualidade de sítio em ecossistemas florestais. Palavras-chave: Floresta Atlântica; atividade microbiana; sucessão ecológica; área degradada.
\end{abstract}

\begin{abstract}
Microbial respiration as indicator of soil quality in forest ecosystem. This research was carried out at the State Forest of Palmito, Paranaguá, PR, Brazil, originally covered with Tropical Atlantic Rainforest. This forest has suffered anthropic degradation, and the goal of this research was to evaluate the response of microorganisms to forest environment changes in the process of regeneration. Three representative areas of the secondary succession of this ecosystem have been selected, where samples of the superficial layer of the soil were collected at the four climatic seasons. The samples were taken from the following soil horizons: F, $\mathrm{H}$ and $\mathrm{A}$. The evaluation of the microbial activity was made by the quantification of microbial respiration. The results shown the production of $\mathrm{CO}_{2}$ on the following sequence: $\mathrm{F}>\mathrm{H}>\mathrm{A}$. And also superior at the advanced phase of the ecological succession, specially at $\mathrm{F}$ horizon. Climatic seasons showed no conclusive effect on the microbial activity. Soil quality amelioration along the forest evolution was characterized by determination of the microbial respiration, suggesting this analyses as an indicator tool of forest site quality.

Keywords: Atlantic Forest; microbial activity; ecological succession; degraded area.
\end{abstract}

\section{INTRODUÇÃO}

A sustentabilidade dos ecossistemas florestais depende, em grande parte, do ciclo biogeoquímico de nutrientes. Esta dependência se manifesta de forma mais intensa nos solos pobres em nutrientes, como é o caso das florestas de planície no litoral paranaense (Britez et al., 1999).

O solo florestal é um habitat que oferece ambiente propício ao desenvolvimento microbiano. E a participação da biota do solo no funcionamento e sustentabilidade dos ecossistemas é bem reconhecida (Mason, 1980). Desta forma, alguns parâmetros referentes à atividade dos microrganismos no solo podem ser utilizados como bioindicadores para avaliação do estado de equilíbrio ou desequilíbrio de 
ecossistemas florestais. O grande desafio da ciência do solo é demonstrar a relação entre níveis de atividade biológica e o funcionamento sustentável dos ecossistemas (Santos e Camargo, 1999).

Os processos microbianos são uma parte integral da qualidade do solo e a atividade dos microrganismos do solo pode servir como indicador biológico para a compreensão da estabilidade e produtividade dentro de um sistema (Turco e Blume, 1999). A microbiota do solo é considerada bioindicador da qualidade do solo (Vargas e Scholles, 2000); é uma medida do status biológico do solo (Santos e Camargo, 1999). Os microrganismos são muito sensíveis e podem ser influenciados pelos fatores bióticos e abióticos ( Vargas e Scholles, 2000; Andrade, 1999). Ainda são escassas as informações sobre o uso de bioindicadores microbiológicos do solo; estudos mais aprofundados são necessários para que se possa interpretar as suas relações com os fatores bióticos e abióticos do solo (Colozzi Filho et al., 1999).

Neste contexto, o presente trabalho teve como objetivo compreender as relações existentes entre a presença e atividade de microrganismos do solo com a recuperação da vegetação da floresta. Assim, em uma cronossequência de fases da sucessão vegetal de Floresta Ombrófila Densa das Terras Baixas, tevese como objetivos específicos: (a) quantificar a respiração microbiana em horizontes superficiais do solo, (b) avaliar o efeito das estações climáticas e das fases sucessionais sobre a respiração microbiana no solo.

\section{MATERIAL E MÉTODOS}

\section{Descrição geral da área de estudo}

A área de estudo está localizada na Planície Pleistocênica do Litoral Paranaense, município de Paranaguá-PR, entre as coordenadas: $25^{\circ} 35^{\prime} \mathrm{S}$ e $48^{\circ} 32^{\prime} \mathrm{W}$. As parcelas experimentais foram instaladas na Floresta Estadual do Palmito, atualmente administrada pelo Instituto Ambiental do Paraná - IAP, como Unidade de Conservação.

A faixa litorânea do estado do Paraná tem seu clima classificado como Af, segundo a classificação de Koepen, que o caracteriza como clima tropical chuvoso, sem estação seca e isento de geadas. Apresenta índices médios de umidade relativa do ar maiores que $86 \%$, em virtude da influência oceânica e da transpiração das matas pluviais existentes (Iapar, 1978; Bigarella, 1978).

No presente trabalho, devido à ausência de dados metereológicos no próprio local de estudo, foram utilizados os dados de temperatura e precipitação pluviométrica obtidos das estações de Morretes (SEAB/PR-IAPAR) e Guaratuba (SIMEPAR/PR) situadas próximas ao local de estudo. Estes dados foram repassados diretamente aos autores do presente trabalho. O comportamento da precipitação e da temperatura durante o período de estudo pode ser observado nas Figuras 1 e 2.

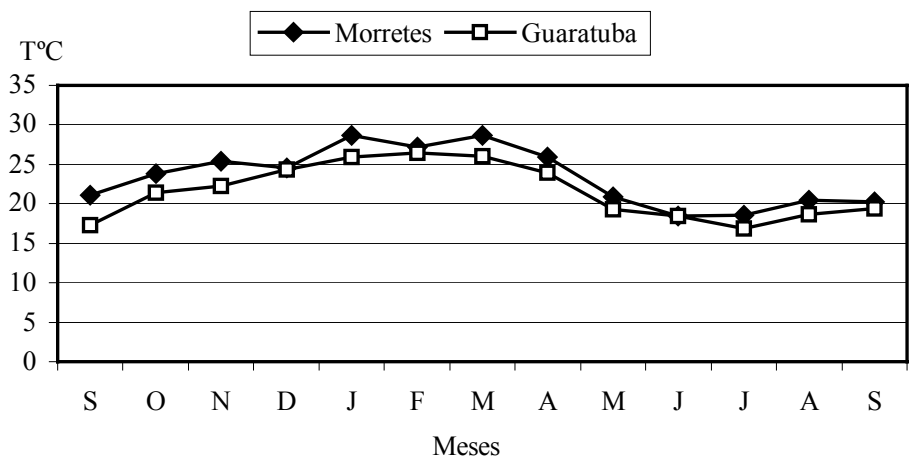

Figura 1. Variação da temperatura média do ar nas estações de Morretes e Guaratuba no período entre setembro de 2000 e setembro de 2001 (SEAB/PR-IAPAR e SIMEPAR/PR).

Figure 1. Average air temperature in Morretes and Guaratuba from September of 2000 to September of 2001 (SEAB/PR-IAPAR and SIMEPAR/PR). 


\section{Vegetação e solo}

A floresta original que inicialmente recobria a área da Floresta do Palmito corresponde à Floresta Ombrófila Densa das Terras Baixas (Veloso et al., 1991), a qual sofreu processo de desmatamento e/ ou retirada de madeira em grande parte de sua área, em diferentes épocas, restando hoje um mosaico de formações vegetacionais correspondentes às diferentes fases da sucessão secundária florestal. As áreas selecionadas para este estudo não têm a sua história bem definida, mas sofreram processo de retirada de madeira e/ou corte raso, com posterior cultivo de mandioca e/ou abacaxi, por cerca de quatro anos. Depois, as áreas foram abandonadas, estabelecendo-se um processo de regeneração natural, encontrandose atualmente em distintos estádios sucessionais. As parcelas selecionadas são representativas de fases da sucessão ecológica deste ecossistema e foram aqui nominadas: Fase Inicial (I), Fase Intermediária (M), Fase Avançada (V), respectivamente com idades estimadas de 20, 33 e 58 anos em 2002. O aumento da biodiversidade e da complexidade estrutural da vegetação é bastante visível a campo, assim como comprova o levantamento fitossociológico (Wisniewski et al., 1997). Isto reflete na camada de serapilheira sobre o solo como pode ser observado na Tabela 1.

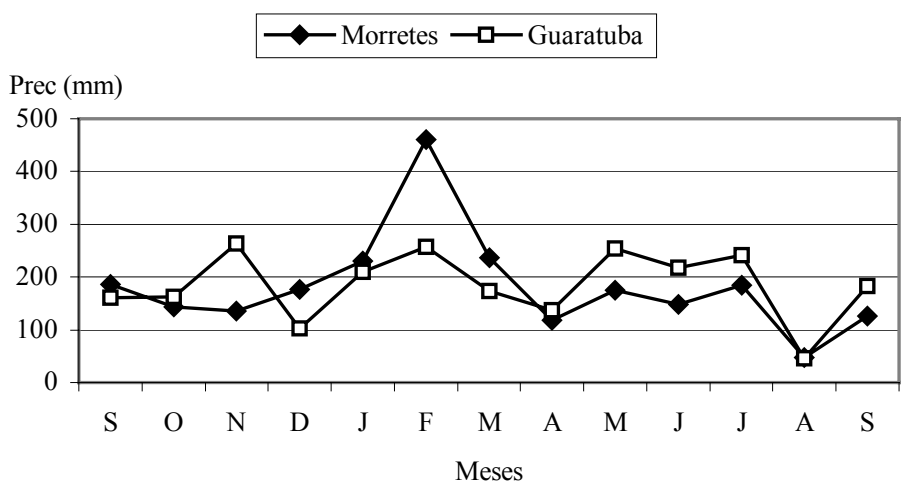

Figura 2. Variação da precipitação pluviométrica mensal nas estações de Morretes e Guaratuba no período entre setembro de 2000 e setembro de 2001 (SEAB/PR-IAPAR e SIMEPAR/PR).

Figure 2. Average bulk precipitation in Morretes and Guaratuba from September of 2000 to September of 2001 (SEAB/PR-IAPAR and SIMEPAR/PR).

Tabela 1. Espessura média da camada de serapilheira $(\mathrm{cm})$ e quantidade média de fitomassa (ton.h ${ }^{-1}$ ) acumulada sobre o solo nas três fases sucessionais.

Table 1. Average thickness of litter layer $(\mathrm{cm})$ and average cumulated litter $\left(\right.$ ton.ha $\left.^{-1}\right)$ on the soil in the three successional phases.

\begin{tabular}{|c|c|c|c|}
\hline Fase Sucessional & Inicial & Intermediária & Avançada \\
\hline Espessura $(\mathrm{cm})$ & $1-3$ & 16 & 21 \\
\hline Quantidade(ton.ha $\left.{ }^{-1}\right)$ & 8,8 & 71,4 & 146,9 \\
\hline
\end{tabular}

Fonte: Wisniewski et al. (1997)

O solo da área de estudo foi classificado como Espodossolo, segundo o atual Sistema Brasileiro de Classificação de Solos (Embrapa, 1999). As principais características físicas e químicas das camadas superficiais do solo podem ser observadas na Tabela 2. 
Tabela 2. Características físicas e químicas do solo mineral superficial em três fases sucessionais da Floresta Estadual do Palmito.

Table 2. Physical and chemical characteristics of the superficial mineral soil in three forest successional phases of the "Floresta Estadual do Palmito".

\begin{tabular}{|c|c|c|c|c|c|c|c|c|c|c|}
\hline $\begin{array}{c}\text { Fase } \\
\text { sucessional }\end{array}$ & $\begin{array}{l}\text { Prof. } \\
(\mathrm{cm})\end{array}$ & $\begin{array}{r}\text { Areia } \\
(\mathrm{g} .1\end{array}$ & $\begin{array}{l}\text { Argila } \\
\left.0 \mathrm{~g}-{ }^{-1}\right)\end{array}$ & $\mathrm{pH}$ & $\begin{array}{r}\mathrm{Ca}+\mathrm{N} \\
\mathrm{cm}\end{array}$ & $\mathrm{m}^{-3}$ & $\begin{array}{c}\mathrm{P} \\
\text { mg.dm }\end{array}$ & $\begin{array}{c}\mathrm{C} \\
\text { g. } \mathrm{dm}^{-3} \\
\end{array}$ & $\begin{array}{c}\mathrm{N} \\
\text { g.kg-1 }\end{array}$ & $\mathrm{C} / \mathrm{N}$ \\
\hline \multirow[t]{3}{*}{ Inicial } & $0,0-2,5$ & 74 & 4 & 3,8 & 5,7 & 0,17 & 11,6 & 65,9 & 1,9 & 35 \\
\hline & $2,5-5,0$ & 88 & 4 & 3,4 & 2,8 & 0,13 & 9,6 & 51,2 & 1,4 & 37 \\
\hline & $5,0-8,0$ & 90 & 4 & 3,3 & 1,6 & 0,09 & 7,4 & 40,9 & 1,2 & 35 \\
\hline \multirow[t]{3}{*}{ Intermediária } & $0,0-2,5$ & 76 & 6 & 2,9 & 1,0 & 0,15 & 7,8 & 71,1 & 2,4 & 30 \\
\hline & $2,5-5,0$ & 88 & 4 & 3,1 & 0,8 & 0,08 & 4,4 & 34,1 & 1,2 & 28 \\
\hline & $5,0-8,0$ & 88 & 2 & 3,2 & 0,7 & 0,06 & 3,2 & 24,6 & 0,8 & 33 \\
\hline \multirow[t]{3}{*}{ Avançada } & $0,0-2,5$ & 78 & 4 & 3,1 & 2,2 & 0,21 & 8,8 & 69,7 & 2,5 & 28 \\
\hline & $2,5-5,0$ & 70 & 4 & 3,1 & 1,2 & 0,12 & 4,8 & 39,6 & 1,6 & 25 \\
\hline & $5,0-8,0$ & 86 & 2 & 3,1 & 0,9 & 0,08 & 3,2 & 29,1 & 1,1 & 26 \\
\hline
\end{tabular}

Fonte: Wisniewski et al. (1997)

\section{Procedimento experimental em campo e laboratório}

Coleta das amostras no campo

Nas parcelas de estudo, foram coletadas amostras de solo ao final de cada uma das estações do ano. Assim: primavera em novembro de 2000; verão em março de 2001; outono em junho de 2001 e inverno em setembro de 2001. A amostragem de solo foi feita coletando-se 10 amostras simples, aleatoriamente, em cada parcela, utilizando-se um coletor cilíndrico metálico com dimensões de $20 \mathrm{~cm}$ de altura e $12 \mathrm{~cm}$ de diâmetro. As 30 amostras simples (10 por fase sucessional) foram conservadas em geladeira de isopor com gelo durante o transporte até o Laboratório de Microbiologia Agrícola, da Pontifícia Universidade Católica do Paraná, para as análises.

Separação dos horizontes de solo

No laboratório, foram retiradas as amostras dos coletores tendo-se cuidado para não desmanchálas. Depois, foram separados os horizontes F (folhas fragmentadas), H (húmus) e A (solo mineral) com ajuda de uma faca. No caso das amostras provenientes da Fase Inicial, o horizonte H não estava totalmente formado, mas o solo apresentava agregados orgânicos com características de horizonte $\mathrm{H}$, misturados à parte mineral do solo (horizonte $\mathrm{A}$ ), os quais foram separados desta com o auxílio de peneira de malha de 2,0 mm. Assim, na Fase Inicial, o horizonte H corresponde a material humificado que estava misturado com o material mineral do solo superficial. As espessuras dos diferentes horizontes foram distintas em cada fase sucessional. Na fase Inicial o horizonte A representava a maior parte do material coletado no cilindro e esta proporção diminuiu sucessivamente nas amostras das Fases Intermediária e Avançada.

\section{Preparo das amostras compostas}

Depois de separadas as camadas, as 10 amostras simples, de cada uma das áreas, foram agrupadas em uma única amostra composta, por camada e por área, de onde foram retiradas as alíquotas para as análises.

Avaliação da quantidade de $\mathrm{CO}_{2}$ liberado pelo solo

A atividade de microrganismos no solo foi avaliada pela liberação de $\mathrm{CO}_{2}$. Com o objetivo de avaliar a variação da atividade microbiana no solo foi utilizada a técnica da respirometria, segundo Öhlinger (1993).

Cada amostra composta foi testada em triplicata e o procedimento experimental foi complementado por prova em branco. Pesou-se $50 \mathrm{~g}$ de solo fresco e colocou-se em frasco hermético. Colocou-se um béquer com $20 \mathrm{~mL}$ de $\mathrm{NaOH}$ 0,5 mol/L em cada frasco; fechou-se hermeticamente; incubou-se a $28{ }^{\circ} \mathrm{C}$ por um período total de 7 dias. Inicialmente, após incubação por 3 dias, o frasco foi 
aberto e imediatamente foi adicionado $1 \mathrm{~mL}$ da solução de $\mathrm{BaCl}_{2} 50 \%$ saturada no béquer, para impedir que o $\mathrm{Na}_{2} \mathrm{CO}_{3}$ formado fosse desdobrado em $\mathrm{NaOH}+\mathrm{CO}_{2}$ novamente, quando da titulação. Retirou-se o béquer do frasco com o auxílio de uma pinça e acrescentou-se 2 a 3 gotas do indicador Fenolftaleína $1 \%$. $\mathrm{O} \mathrm{NaOH}$ não utilizado durante a incubação da amostra de solo, foi titulado com $\mathrm{HCl} 0,5 \mathrm{~mol} / \mathrm{L}$ até o desaparecimento da cor rósea. Anotou-se a quantia de $\mathrm{HCl}$ gasto na titulação. Após a leitura, correspondente aos 3 dias de incubação, novamente colocou-se um béquer com $\mathrm{NaOH}$ em cada frasco, fechou-se hermeticamente, incubou-se por mais 4 dias e foi feita a titulação. Procedeu-se aos cálculos da quantidade de $\mathrm{CO}_{2}$ liberado por grama de solo seco, durante o período de incubação de 7 dias. Para determinação da umidade foram retiradas alíquotas das amostras compostas de solo fresco, as quais foram pesadas, colocadas para secar a $105^{\circ} \mathrm{C}$, até peso constante, sendo a umidade determinada por gravimetria.

\section{Análises estatísticas}

Para análise estatística dos dados obtidos, foi adotado o delineamento tri-fatorial, sendo os fatores respectivos aos horizontes do solo florestal (3), às fases da sucessão ecológica na floresta (3) e às estações do ano (4). Para cada combinação entre os níveis de fatores, foram efetuadas três repetições analíticas. A variável analisada foi a atividade microbiana, através da medição da respiração microbiana. Foi feita a ANOVA para esta variável e, quando a análise de variância mostrou que as médias entre tratamentos não eram estatisticamente iguais, foi aplicado o teste Tukey ao nível de 5\% de significância para comparação das médias, duas a duas.

\section{RESULTADOS E DISCUSSÃO}

Os resultados médios sobre a produção de $\mathrm{CO}_{2}$, nos horizontes do solo, segundo as épocas do ano, podem ser vistos na Tabela 3. A ANOVA acusou efeito significativo dos horizontes de solo e das fases sucessionais; neste último caso, havendo interação com os horizontes do solo. No caso das estações do ano, foram observadas diferenças estatísticas de difícil compreensão, como será discutido adiante.

Tabela 3. Produção média de $\mathrm{CO}_{2}$ microbiano em amostras de três horizontes do solo florestal, em três fases da sucessão florestal, nas quatro estações do ano.

Table 3. Average production of microbial $\mathrm{CO}_{2}$ in samples of three forest soil layers in three forest successional phases, in four seasons of the year.

\begin{tabular}{llllll}
\hline \multirow{2}{*}{ Horizontes } & \multicolumn{5}{c}{$\mathrm{mg} \mathrm{CO} \mathrm{dia}^{-1} 100 \mathrm{~g} \mathrm{solo}^{-1 .}$} \\
& \multirow{2}{*}{ Fase sucessional } & $\begin{array}{l}\text { Nov/2000 } \\
\text { Primavera }\end{array}$ & $\begin{array}{l}\text { Mar/2001 } \\
\text { Verão }\end{array}$ & $\begin{array}{l}\text { Jun/2001 } \\
\text { Outono }\end{array}$ & $\begin{array}{c}\text { Set/2001 } \\
\text { Inverno }\end{array}$ \\
\hline Folha (F) & Inicial (I) & 145,64 & 162,24 & 156,02 & 128,87 \\
& Intermediária (M) & 249,27 & 201,3 & 238,19 & 234,46 \\
& Avançada (V) & 267,9 & 217,04 & 248,23 & 261,21 \\
\hline Húmus (H) & Inicial (I) & 16,41 & 17,82 & 33,53 & 26,07 \\
& Intermediária (M) & 58,66 & 68,08 & 51,26 & 53,13 \\
& Avançada (V) & 51,25 & 42,19 & 53,5 & 68,6 \\
\hline Mineral (A) & Inicial (I) & 3,89 & 6,05 & 5,28 & 7,48 \\
& Intermediária (M) & 5,12 & 2,84 & 2,65 & 2,66 \\
& Avançada (V) & 5,37 & 5,74 & 4,65 & 2,3 \\
\hline
\end{tabular}

\section{Horizontes do solo e respiração microbiana}

Com relação ao efeito dos horizontes do solo, de uma maneira geral, observa-se que existe um gradiente de produção de $\mathrm{CO}_{2}$ entre as camadas do solo na seguinte ordem: $\mathrm{F}>\mathrm{H}>\mathrm{A}$. Isto indica que a atividade microbiana está concentrada principalmente nas camadas orgânicas do solo. Este fato já era esperado, pois é nesta camada do solo onde se encontra a maior quantidade de compostos orgânicos que estimulam o crescimento dos microrganismos. O teor de matéria orgânica nos diferentes horizontes, nas três fases sucessionais pode ser observado na Tabela 4. Lima et al. (2001), na mesma área de estudo, no ano 2001, já haviam identificado este mesmo gradiente de produção de $\mathrm{CO}_{2}$ com respeito aos horizontes 
de solo.

Tabela 4. Teor de matéria orgânica (\%) nos horizontes do solo, das diferentes fases sucessionais.

Table 4. Organic matter concentration (\%) in the soil horizons of the different successional phases.

\begin{tabular}{llllllllll}
\hline Fase sucessional & \multicolumn{3}{c}{ Inicial } & \multicolumn{4}{c}{ Intermediária } & \multicolumn{3}{c}{ Avançada } \\
\hline Horizontes do solo & F & H & A & F & H & A & F & H & A \\
Matéria orgânica (\%) & 76,4 & 13,4 & 5,1 & 96,0 & 33,7 & 5,3 & 95,6 & 58,7 & 4,7 \\
\hline Fonte: Peña (2002) & & & & & & & & &
\end{tabular}

No horizonte $\mathrm{F}$, ocorre o processo de biodegradação mais expressivo. No $\mathrm{H}$, encontram-se os compostos mais resistentes, onde a atuação microbiana fica mais restrita aos microrganismos especialistas. No horizonte A, os teores de carbono e nutrientes são bem inferiores, o que explica a menor atividade microbiana. Além disso, os horizontes $\mathrm{F}$ e $\mathrm{H}$ apresentaram raízes, as quais podem estimular o desenvolvimento e atividade dos microrganismos. Segundo Colozzi Filho et al. (1999), as raízes são fonte de carbono no solo que estimulam a atividade microbiana. Andrade (1999) afirma que o ambiente ao redor das raízes representa uma região de intensa atividade microbiana, onde as interações microrganismo-microrganismo e microrganismo-planta são evidentes e extremamente complexas. Os exsudatos das plantas estimulam a atividade microbiana associada à rizosfera (Santos e Camargo, 1999). Segundo Cattelan et al. (1997) e Andrade (1999), os exsudatos são mais prontamente disponíveis do que os restos vegetais. As raízes também exercem influência sobre as trocas gasosas no solo.

Observações de outros autores também concordam com os dados obtidos neste trabalho. Segundo Colozzi Filho et al. (1999) e Vargas e Scholles (2000), a permanência dos resíduos na superfície propicia aumentos na atividade biológica nas camadas superficiais do solo, dinâmica que se desenvolve sob maior umidade, menor temperatura e maior teor de matéria orgânica. Para Vargas e Scholles (2000), as diferenças na atividade microbiana ao longo do perfil do solo refletem a distribuição dos resíduos vegetais.

A relação entre a atividade microbiana e a umidade do meio tem sido mostrada em vários trabalhos (Tiwari et al., 1987; Barros et al., 1995; Prado e Airoldi, 1999). Este efeito da umidade, comentado pelos últimos autores, pode ter contribuído, adicionalmente, para estas diferenças entre horizontes. O mesmo gradiente foi observado para os valores de umidade, ou seja, $\mathrm{F}>\mathrm{H}>\mathrm{A}$ (Tabela 5).

Tabela 5. Umidade média $\left(\mathrm{g} \mathrm{H}_{2} \mathrm{O} .100 \mathrm{~g}\right.$ solo $\left.\mathrm{seco}^{-1}\right)$ nos horizontes do solo florestal das três fases sucessionais, nas diferentes estações do ano.

Table 5. Average moisture $\left(\mathrm{g} \mathrm{H}_{2} \mathrm{O} .100 \mathrm{~g}\right.$ dry soil $\left.{ }^{-1}\right)$ in the forest soil horizons of the three successional phases, at the different climatic seasons.

\begin{tabular}{llcccc}
\hline \multirow{2}{*}{ Horizontes } & \multirow{2}{*}{ Fase sucessional } & Estações do ano \\
& & Primavera & Verão & Outono & Inverno \\
\hline Folha (F) & Inicial (I) & 67,90 & 40,53 & 64,74 & 30,58 \\
& Intermediária (M) & 220,25 & 105,51 & 146,06 & 128,83 \\
& Avançada (V) & 269,00 & 131,48 & 193,26 & 166,67 \\
\hline \multirow{2}{*}{ Húmus (H) } & Inicial (I) & 22,36 & 15,71 & 35,06 & 35,98 \\
& Intermediária (M) & 105,86 & 125,63 & 72,89 & 71,35 \\
& Avançada (V) & 167,32 & 128,83 & 182,17 & 181,06 \\
\hline \multirow{2}{*}{ Mineral (A) } & Inicial (I) & 12,65 & 5,04 & 9,53 & 11,63 \\
& Intermediária (M) & 11,10 & 12,89 & 9,84 & 10,4 \\
& Avançada (V) & 42,29 & 27,36 & 43,06 & 29,13 \\
\hline
\end{tabular}

Fonte: Peña (2002)

\section{Sucessão ecológica e respiração microbiana}

$\mathrm{O}$ efeito da sucessão ecológica na produção de $\mathrm{CO}_{2}$ nos diferentes horizontes do solo pode ser 
visualizado na Figura 3.

FLORESTA, Curitiba, PR, v.35, n. 1, jan./abr. 2005.

Peña, M.L.P.; Marques, R.; Jahnel, M. C.; Anjos, A. dos 


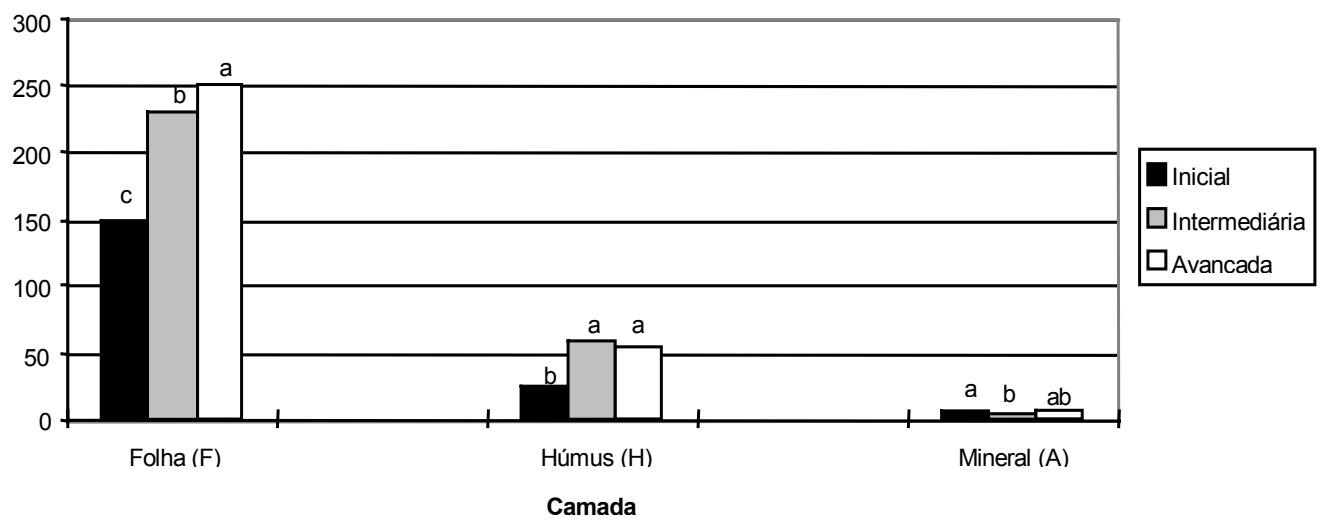

Figura 3. Efeito das fases sucessionais na produção média de $\mathrm{CO}_{2}$ microbiano $\left(\mathrm{mg} \mathrm{CO}_{2}\right.$ dia-1 $100 \mathrm{~g}$ solo seco-1) em amostras de três horizontes do solo florestal.

Figure 3. Sucessional phase effect on the average production of microbial $\mathrm{CO}_{2}\left(\mathrm{mg} \mathrm{CO}_{2}\right.$ dia-1 $100 \mathrm{~g}$ dry soil-1) in samples of three layers of forest soil.

(Letras iguais nas colunas, no mesmo horizonte, não diferem significativamente entre si pelo teste de Tukey, ao nível de 5\%),

Os valores da Figura 3 mostram que na camada $\mathrm{F}$ e na camada $\mathrm{H}$ a produção de $\mathrm{CO}_{2}$ aumentou com a evolução da sucessão florestal, isto sendo mais evidente na camada $\mathrm{F}$. Na camada $\mathrm{A}$, não foi observado o efeito das fases sucessionais na produção de $\mathrm{CO}_{2}$. Este mesmo comportamento também havia sido observado por Lima et al. (2001).

Nos horizontes orgânicos do solo, vários fatores devem ter contribuído para os resultados observados. A espessura da serapilheira (Tabela 1), o teor de matéria orgânica (Tabela 4) e a umidade nas amostras (Tabela 5) mostraram aumento com a evolução sucessional, contribuindo para os maiores valores de produção de $\mathrm{CO}_{2}$ nas amostras das fases mais avançadas da vegetação. Estas diferenças entre as diferentes fases sucessionais são resultantes do processo evolutivo da floresta. Wisniewski et al. (1997) descrevem que, com o avanço da sucessão, aumenta a diversidade de espécies, o número de famílias e de árvores mortas, indicando substituição de espécies. Além disso, aumenta a regeneração, o número de indivíduos e de estratos. Também aumenta a estrutura da comunidade vegetal, a altura e diâmetro dos seus troncos. Em conseqüência disso, o sub-bosque fica mais denso, o solo mais coberto pela vegetação, diminuem as clareiras, concorrendo para o sombreamento; diminui a ação eólica e a umidade no interior da floresta aumenta. Igualmente, aumenta-se a adição de matéria orgânica, a espessura de camada orgânica e os horizonte orgânicos evoluem com a sub-divisão em horizontes F e H mais pronunciados (Wisniewski et al., 1997; Pinto, 2001).

Borges et al. (1999) observaram que a cobertura vegetal é um fator determinante sobre a atividade microbiana. Do mesmo modo, Colozzi Filho et al. (1999) afirmaram que a permanência de resíduos na camada superficial diminui as oscilações de temperatura e umidade na superfície do solo, além de estimular as comunidades microbianas.

A composição química da serapilheira muda com a evolução da sucessão. Pinto (2001), também pesquisando na mesma floresta, mostrou que os teores de $\mathrm{N}$ e $\mathrm{K}$ aumentam na fase avançada da sucessão, o que certamente favorece a atividade microbiana. Outro aspecto importante diz respeito à qualidade do material de serapilheira. Boeger (2000), também na mesma área deste estudo, observou que a esclerofilia dos tecidos foliares das plantas tende a diminuir com o avanço da sucessão, o que certamente favorece o ataque microbiano ao material vegetal das fases mais avançadas.

Para Vargas e Scholles (2000), a diversidade vegetal altera a composição da comunidade microbiana, estimulando a biodiversidade microbiana. Segundo Cattelan et al. (1997), a diversidade vegetal é importante para a manutenção e o aumento da diversidade do solo, fazendo com que o solo seja biologicamente mais ativo.

Assim, na Fase Inicial da sucessão, a baixa capacidade produtiva ou baixa qualidade do solo é refletida na menor atividade microbiana. À medida que a vegetação evoluiu, a qualidade do sítio melhorou e isto foi diagnosticado indiretamente pelos valores superiores de respiração microbiana do 
solo, caracterizando a mesma como um bom indicador microbiológico da qualidade do solo. No caso específico do ambiente em estudo, isto só ficou claro nos horizontes orgânicos do solo.

\section{Estação do ano e respiração microbiana}

Os resultados mostrados na Tabela 3 permitem visualizar a variação dos valores de produção de $\mathrm{CO}_{2}$ nas amostras de horizontes do solo, coletadas nas diferentes épocas do ano. Apesar da ANOVA ter acusado efeito deste fator (estação do ano) sobre a variável produção de $\mathrm{CO}_{2}$, as diferenças não são de todo compreensíveis e nem podem ser atribuídas às variações de precipitação e temperatura observadas na região de estudo (Figuras 1 e 2). Não foram observadas correlações positivas ou negativas entre as variáveis climáticas e a atividade microbiana.

Esperava-se observar, neste estudo, variações na produção de $\mathrm{CO}_{2}$ ao longo das estações climáticas. Para Vargas e Scholles (2000) e Andrade (1999), os microrganismos são muito sensíveis e podem ser influenciados pelos fatores bióticos e abióticos. As condições ambientais estimulam ou inibem o desenvolvimento e atividade de cada um dos grupos de microrganismos. Segundo Mason (1980) e Santos e Camargo (1999), das variáveis climáticas, a precipitação e a temperatura são as que exercem maior influência.

No caso do horizonte $\mathrm{F}$, os maiores valores observados na primavera poderiam, em parte, ser explicados pelo maior aporte de serapilheira, que inicia-se nesta época do ano, no local de estudo (Pinto, 2001). A deposição de flores também é mais volumosa neste período. Este material orgânico lábil poderia induzir diferenças na respiração microbiana, pois pode servir de substrato aos microrganismos. No caso dos demais horizontes ( $\mathrm{H}$ e A), as variações no conteúdo de material orgânico não se processam ao longo das estações mas sim ao longo de vários anos, o que pode explicar a inexistência de efeito estacional claro.

A inexistência de diferenças significativas entre as épocas do ano pode também estar relacionada com a técnica utilizada. A avaliação da produção de $\mathrm{CO}_{2}$ em laboratório dificulta a avaliação do efeito estacional pois, no procedimento analítico, a temperatura é mantida constante. Os resultados sobre a população microbiana (número mais provável de fungos e bactérias) também não sofreram efeito estacional (Peña, 2002). Apesar destes não serem os únicos organismos responsáveis pela respiração do solo, isto, em parte, corrobora os resultados de produção de $\mathrm{CO}_{2}$.

\section{CONCLUSÕES}

Dos resultados obtidos neste trabalho pode-se concluir que:

- A produção de $\mathrm{CO}_{2}$ nas camadas superficiais do solo sofre influência direta da quantidade e da qualidade da matéria orgânica presente;

- A maior produção de $\mathrm{CO}_{2}$ na Fase Avançada da sucessão e na camada $\mathrm{F}$ do solo é resultante da combinação entre substrato de boa qualidade e microclima adequado para a atividade microbiana;

- A variação da atividade microbiana nas camadas superficiais do solo, ao longo das estações do ano, não pôde ser avaliada eficientemente pela técnica laboratorial empregada;

- A produção de $\mathrm{CO}_{2}$ mostrou-se como um bom indicador microbiológico para caracterizar qualidade de um solo florestal, quando esta é avaliada nos horizontes orgânicos do solo.

\section{REFERÊNCIAS}

ANDRADE, G. Interacciones microbianas en la rizosfera. In: SIQUEIRA, J. O.; MOREIRA, F. M. S.; LOPES, A. S.; GUILHERME, L. R. G.; FAQUIN, V.; FURTINI NETO, A. E.; CARVALHO, J. G. (Ed.). Inter-relação fertilidade, biologia do solo e nutrição de plantas: Soil fertility, soil biology, and plant nutrition interrelationships. Viçosa: SBCS, Lavras: UFLA/DCS, 1999. p. 551 - 575.

BARROS, N.; GOMEZORELLANA, I.; FEIJOO, S.; BALSA, R. The effect of soil-moisture on soil microbial activity studied by microcalorimetry. Thermochimica Acta. v. 249, p. 161-168, 1995.

BIGARELla, J. J. A Serra do Mar e a porção oriental do estado do Paraná. Curitiba: Governo do Estado do Paraná - ADEA, 1978.

BOEGER, M. R. T. Morfologia foliar e aspectos nutricionais de espécies arbóreas em três estádios 
sucessionais, de Floresta Ombrófila Densa das Terras Baixas, Paranaguá, PR. Curitiba, 2000. 150f. Tese (Doutorado em Engenharia Florestal), Setor de Ciências Agrárias, Universidade Federal do Paraná.

BORGES, A. L.; KIEHL, J. C.; SOUZA, L. S. Alteração de propriedades físicas e atividade microbiana de um latossolo amarelo álico após o cultivo com fruteiras perenes e mandioca. Revista Brasileira de Ciência do Solo, v. 23, p.1019-1025. 1999.

BRITEZ, R. M.; MARQUES, R.; PIRES, L.; BASSFELD, J. C.; BONET, B. R.; LOPEZ, M. R. Decomposição de serapilheira e liberação de nutrientes em florestas da planície litorânea da Ilha do Mel, PR, Brasil. In: CONGRESSO LATINOAMERICANO DE LA CIENCIA DEL SUELO, 14., 1999, Pucon. Anais ... Temuco: Universidad de la Forntera, 1999. p. 569.

CATTELAN, A. J.; GAUDÊNCIO, C. A.; SILVA, T. A. Sistemas de rotação de culturas em plantio direto e os microrganismos do solo, na cultura da soja, em Londrina. Revista Brasileira de Ciência do Solo, Campinas, v. 21, p. 293-301, 1997.

COLOZZI FILHO, A.; BALOTA, E. L.; ANDRADE, D. de S. Microrganismos e processos biológicos no sistema plantio direto. In: SIQUEIRA, J. O.; MOREIRA, F. M. S.; LOPES, A. S.; GUILHERME, L. R. G.; FAQUIN, V.; FURTINI NETO, A. E.; CARVALHO, J. G. (Ed.). Inter-relação fertilidade, biologia do solo e nutrição de plantas: Soil fertility, soil biology, and plant nutrition interrelationships. Viçosa: SBCS, Lavras: UFLA/DCS, 1999. p. 487 - 508.

EMBRAPA. Sistema brasileiro de classificação de solos. Brasília: Embrapa Solos, Rio de Janeiro, 1999.

IAPAR. Cartas climáticas básicas do estado do Paraná. Londrina: IAPAR, 1978.

LIMA, P. H. C.; VIEIRA, M. E. M.; MARQUES, R. Atividade microbiana em frações da camada superficial de Espodossolo sob Floresta Ombrófila Densa no Paraná. In: CONGRESSO BRASILEIRO DE CIÊNCIA DO SOLO, 28., 2001, Londrina. Anais... Londrina: Embrapa Soja - IAPAR - UEL - UEM - SBCS, 2001. p. 89.

MASON, C. F. Decomposição. São Paulo: Ed. da Universidade de São Paulo, 1980.

ÖHLINGER, R. Bestimmung der Bodenatmung im Laborversuch. In: SCHINNER, F.; ÖHLINGER, R.; KANDELER, E.; MARGESIN, R. (Ed.). Bodenbiologische Arbeitsmethoden. Berlin: Springer-Verlag, 1993.

PEÑA, M. L. P. Indicadores microbiológicos de solo na avaliação da recuperação de área degradada de Floresta Ombrófila Densa das Terras Baixas no Litoral Paranaense - Brasil. Curitiba, 2002. 88p. Dissertação (Mestrado em Ciência do Solo). Setor de Ciências Agrárias, Universidade Federal do Paraná.

PINTO, C. Contribuição de espécies arbóreas de diferentes fases sucessionais da Floresta Ombrófila Densa das Terras Baixas para ciclagem de nutrientes minerais, Floresta Estadual do Palmito, Paranaguá, PR. Curitiba, 2001. 68p. Dissertação (Mestrado em Engenharia Florestal), Setor de Ciências Agrárias, Universidade Federal do Paraná.

PRADO, A. G. S.; AIROLDI, C. The influence of moisture on microbial activity of soils. Thermochimica Acta, v.332, p. 71-74, 1999.

SANTOS, G. A.; CAMARGO, F. A. O. Fundamentos da matéria orgânica do solo: ecossistemas tropicais e subtropicais. 1.ed. Porto Alegre: Genesis Edições, 1999.

TIWARI, S. C.; TIWARI, B. K.; MISHRA, R. R. The influence of moisture regimes on the population and activity of soil-microorganisms. Plant and Soil, v.101, n.1, p. 133-136, 1987.

TURCO, R. F.; BLUME, E. Indicators of soil quality. In: SIQUEIRA, J. O.; MOREIRA, F. M. S.; LOPES, A. S.; GUILHERME, L. R. G.; FAQUIN, V.; FURTINI NETO, A. E.; CARVALHO, J. G. (Ed.). Inter-relação fertilidade, biología do solo e nutrição de plantas: Soil fertility, soil biology, and plant nutrition interrelationships. Viçosa: SBCS, Lavras: UFLA/DCS, 1999. p. 529 - 550. 
VARGAS, L. K.; SCHOLLES, D. Biomassa microbiana e produção de $\mathrm{C}_{-} \mathrm{CO}_{2}$ e $\mathrm{N}$ mineral de um podzólico vermelho-escuro submetido a diferentes sistemas de manejo. Revista Brasileira de Ciência do Solo, v. 24, p. 35-42. 2000.

VELOSO, H. P.; RANGEL FILHO, A. L. R.; LIMA, J. C. A. Classificação da vegetação brasileira, adaptada a um sistema universal. Rio de Janeiro: IBGE - Departamento de Recursos Naturais e Estudos Ambientais, 1991. 124p.

WISNIEWSKI, C.; ZILLER, S. R.; CURCIO, G. R.; RACHWAL, M. F. G.; TREVISAN, E.; SOUZA, J. $P$. Caracterização do ecossistema e estudo das relações solo-cobertura vegetal em Planície Pleistocênica do Litoral Paranaense. Curitiba: Universidade Federal do Paraná, 1997. 55 p. (CNPq). Relatório Técnico Final. 